\title{
O conceito de ilusão em psicanálise: estado ideal ou espaço potencial?
}

\author{
Claudia Amorim Garcia \\ Pontifícia Universidade Católica do Rio de Janeiro
}

\begin{abstract}
Resumo
Este trabalho discute diferentes interpretações da noção de ilusão na psicanálise contemporânea. Primeiramente retoma as considerações de Freud sobre a relevância da ilusão na construção da cultura, que culminam com sua posição final contida no texto de 1927. A seguir, apresenta dois desdobramentos teóricos bastantes distintos da noção de ilusão representados pelos conceitos de área da ilusão, em D. Winnicott, e domínio da ilusão, em J. Chasseguet-Smirgel. Finalmente, discute comparativamente as definições de ilusão em D. Winnicott e J. Chasseguet-Smirgel, sugerindo, na conclusão, que ambos contribuem para uma reflexão psicanalítica sobre o normal e o patológico na sociedade atual.
\end{abstract}

Palavras-chave: ilusão; pulsão; domínio da ilusão; espaço potencial

\begin{abstract}
The concept of illusion in psychoanalysis: ideal state or potential space? This paper discusses different interpretations of the notion of illusion in contemporary psychoanalysis. First, it resumes Freud's contributions about the main role of illusion in the building up of civilization which reaches its highest point in 1927 with his final definition of illusion. Next, it presents two different theoretical developments of the notion of illusion represented by D. Winnicott's area of illusion and J. Chasseguet-Smirgel's realm of illusion. Finally, it discusses comparatively D. Winnicott's and J. Chasseguet-Smirgel's definitions of illusion, suggesting that both contribute to a better understanding of pathology and normality in contemporary society.
\end{abstract}

Keywords: illusion; drive; area of illusion; realm of illusion

A psicanálise atribui à ilusão um significado radicalmente diferente daquele encontrado na linguagem cotidiana, na medida em que desconsidera suas relações com a verdade, a realidade externa e o erro. O conceito psicanalítico de ilusão não diz respeito à definição sobre a verdade ou a falsidade de um enunciado, mas à sua potencialidade psíquica, isto é, sua capacidade de causação psíquica. Assim, a definição de ilusão, em psicanálise, subverte sua acepção corriqueira já que positiva o conceito que passa a ser entendido como a expressão legítima de uma realidade incontestável - a realidade psíquica. A ordem da ilusão é, por excelência, a ordem do psíquico, do singular e, portanto, daquilo que não é passível de erro ou equívoco, no sentido da linguagem comum. A virada conceitual que culmina com a subversão do conceito de ilusão em psicanálise tem sua origem em Freud, mas resultou em vários desdobramentos na produção psicanalítica pós-freudiana. Aqui, discutiremos principalmente as contribuições bastante diferentes de Winnicott e Chasseguet-Smirgel que, apesar das divergências entre eles, se derivam de uma matriz comum, sendo ambos, portanto, tributários do texto freudiano.

O conceito de ilusão em Freud (1920/1976, 1921/1976,
19271974, 1933/1976) é marcado pelo componente realização de desejo, mencionado toda vez que o tema é discutido. As formações ilusórias, portanto, sempre expressam um desejo, o que justifica sugerir que a problemática da ilusão já se faz presente no texto freudiano desde o final do século XIX, especialmente na Interpretação dos Sonhos. No entanto, é apenas em 1908, quando ele discute as relações entre o brincar, a fantasia e a criação literária, que a noção de ilusão pode ser, a posteriori, inferida. Naquela ocasião, Freud afirma que a fantasia do adulto é o substituto do brincar infantil, e dela o escritor criativo faz uso na construção de uma obra literária, possibilitando ao leitor o acesso a satisfações proibidas que as fantasias representam. A afirmação de que a linha de continuidade entre o brincar das crianças e as fantasias dos adultos consiste na realização de desejos que ambos representam antecipa sua discussão sobre a ilusão em trabalhos posteriores.

Em 1914, o tema da satisfação de desejo é retomado no bojo da discussão sobre a formação do ideal, representante da tentativa de recuperação do narcisismo perdido da infância quando o eu era seu próprio ideal (Freud, 1914/1974, p. 111). Neste sentido, o ideal do ego ${ }^{1}$ apontaria para o desejo de 
reencontro com a experiência mítica de completude e perfeição própria do narcisismo primário, mas - e esta é a novidade de 1914 que nos interessa - também se constitui numa defesa contra o reconhecimento do desamparo e da dependência que ameaçam o universo de completude narcísica. Em 1914, portanto, a realização de desejo que caracteriza o que viria a ser conceituado como ilusão, passa a ser considerada também como uma proteção compensatória e uma manobra defensiva contra a inevitabilidade da dependência e do desamparo. $\mathrm{O}$ componente defensivo, que é então introduzido, passa, daí em diante, a ocupar lugar central na noção de ilusão, que aparece pela primeira vez em 1920, como parte do argumento segundo o qual a vida psíquica e seu movimento contínuo de transformação resultam, inexoravelmente, da dialética entre o recalque e as pulsões (Freud, 1920/1976, p. 61). Freud se refere, então, explicitamente, a uma ilusão benévola (p. 60) representada pelo desejo persistente entre os humanos de acreditar numa pulsão para a perfeição, que os protegeria do duplo reconhecimento de que a vida é um curto intervalo no caminho para a morte e da existência da pulsão de morte. Neste sentido, ilusão em 1920 representa principalmente a tentativa de negar a ordem pulsional, principalmente no que se refere à compulsão à repetição e à pulsão de morte, e aponta para um estado de coisas livre do conflito e da agressividade, anunciando a discussão de 1921. O desejo contido na ilusão benévola se apresenta como uma defesa e em oposição ao movimento da pulsão em direção a um estado anterior de coisas, diferentemente do que havia sido defendido em 1914, quando o que dominava era justamente o desejo de retorno a um estado anterior de completude narcísica. Esta reviravolta argumentativa crucial, determinada pela introdução do conceito de pulsão de morte, não elimina, no entanto, o caráter de oposição presente nas duas formulações.

Realização de desejo e proteção são componentes que se articulam na elaboração da noção de ilusão em 1921, peça importante na discussão sobre o funcionamento de grupos nos quais prevalece tanto a tentativa de preservação do princípio do prazer quanto à crença no amor do líder. Os indivíduos no grupo compartilham do sentimento de onipotência, não toleram o adiamento da satisfação, são impulsivos e influenciáveis, demonstrando, assim, que funcionam dentro de um registro marcadamente narcísico e, portanto, hostil à constituição de vínculos grupais. É assim, então, que a crença no amor do chefe, agora no lugar de ideal do eu, vem cumprir a função de proteção contra a hostilidade inerente ao narcisismo, possibilitando a formação do grupo. A hipótese de Freud é de que a estrutura grupal é garantida pelas identificações verticais dos membros do grupo com o líder, e horizontais, entre eles, ambas sustentadas pela ilusão de serem amados pelo líder. Aqui, portanto, ilusão representa não apenas a tentativa de resistir à instauração do principio da realidade e, conseqüentemente, o desejo narcísico de preservação do princípio do prazer, mas, também, a possibilidade de sustentação do laço social através da crença no amor do chefe. É justamente a concepção da ilusão como locus de origem das formações culturais vis a vis seu aspecto protetor e defensivo que constitui o núcleo da discussão do "Futuro de uma ilusão" (Freud, 1927/1974), texto no qual, finalmente, uma definição formal da ilusão é encontrada.
A tendência a considerar a ilusão como uma defesa contra o reconhecimento do caráter efêmero e transitório da vida humana, assim como o solo do qual se originam as formações culturais, constitui o centro da discussão em 1927, texto no qual Freud discute o acervo psíquico da civilização: os ideais, a arte e a religião. Enquanto os ideais representam a preservação das mais sublimes aquisições humanas, a criação artística e, mais especificamente, a religião são consideradas como artefatos compensatórios que protegem os humanos do desamparo, reconciliando-os com os sacrifícios que a civilização exige. A persistência das crenças religiosas, apesar de seu caráter irracional e da fé incondicional que demandam, é prova evidente, para Freud, de que a religião se sustenta na ilusão, o que justificaria sua força e importância na comparação com as outras aquisições culturais. É, então, no contexto da discussão sobre a inevitabilidade da religião e de seu componente realização de desejo que Freud, finalmente, apresenta uma definição de ilusão que já vinha se anunciando há pelo menos uma década.

Quando digo que todas essas coisas são ilusões, devo definir o significado da palavra. Uma ilusão não é a mesma coisa que um erro, nem tampouco um erro. (...) O que é característico das ilusões é o fato de derivarem de desejos humanos. (...) As ilusões não precisam ser necessariamente falsas, ou seja, irrealizáveis, ou em contradição com a realidade (...) Podemos, portanto, chamar uma crença de ilusão quando uma realização de desejo constitui fator proeminente em sua motivação e, assim, procedendo, desprezamos suas relações com a realidade, tal como a própria ilusão não dá valor à verificação. (Freud, 1927/1974. p. 43)

A trajetória conceitual na construção do conceito de ilusão havia chegado a seu término. O componente realização de desejo, já presente em 1908, é explicitamente considerado o núcleo da ilusão em 1927, e a religião entendida como a ilusão prototípica no sentido de que se deriva do desejo humano de proteção e responde ao anseio pelo pai, resquício da experiência primária de desamparo. Neste sentido, a religião e os ideais ambos pertencem ao universo da ilusão, na medida em que são manifestações da tentativa de preservar um estado de coisas narcísico, ao mesmo tempo em que compensam os limites impostos pelo princípio da realidade.

Vai nesta mesma direção a concepção de ilusão que aparece nas "Novas conferências introdutórias", em que o conceito é mencionado em relação ao desejo de acreditar que a bondade constitui o âmago do humano.

Infelizmente o que a História nos conta e o que nós mesmos temos experimentado não fala nesse sentido, mas, antes, justifica a conclusão de que a crença na bondade da natureza humana é uma dessas perniciosas ilusões com as quais a humanidade espera seja sua vida embelezada e facilitada, enquanto, na realidade, só causam prejuízo. (Freud, 1933/1976, p. 130) [itálicos meus]

Em síntese, para Freud o conceito de ilusão expressa o desejo de negar o desamparo, a ordem pulsional e o conflito assim como a tentativa de preservação do princípio do prazer e da completude narcísica. Ilusão representa, portanto, uma proteção contra as 
imposições do princípio da realidade e o reconhecimento da castração e, neste sentido, pode ser entendida como um elemento defensivo e alienante no movimento de constituição subjetiva. $\mathrm{O}$ argumento freudiano, no entanto, enfatiza a dialética dos opostos e o papel da negatividade, mostrando o lugar central do conflito na origem da ilusão. Assim, o desejo de preservação de um estado de coisas ideal se opõe à inevitabilidade do desamparo e das pulsões, especialmente da pulsão de morte, e é justamente este antagonismo que resulta no caráter potencialmente produtivo da ilusão como origem do laço social e das formações culturais que, em última análise, protegem do desamparo. É, portanto, somente a partir do reconhecimento da relação antagônica entre o desejo e seu oposto que podemos apreender a especificidade do conceito de ilusão em Freud. Chasseguet-Smirgel e Winnicott vão, cada um a seu modo, se apropriar das duas polaridades contidas na definição freudiana, e a partir delas desenvolver concepções singulares e radicalmente diferentes sobre a ilusão, tema que exaustivamente discutiram nos seus escritos.

\section{O universo da ilusão e o estado ideal de coisas}

Chasseguet-Smirgel (1971/1984, 1975/1985, 1976; 1986) também considera que Ilusão ${ }^{2}$ é o universo da realização de desejo e nenhum valor atribui à realidade externa na sua discussão sobre o tema. Assim, Ilusão é a expressão da tentativa de retorno mítico à situação inicial de fusão com a mãe, anterior ao desamparo, cuja dissolução resultaria na constituição do ideal do eu, representante, portanto, do desejo regressivo de fusão. Assim, enquanto para Freud ilusão é o movimento de negar a compulsão à repetição própria das pulsões e a imposição do princípio da realidade, que acaba resultando na construção da cultura, para Chasseguet-Smirgel Ilusão é a busca compulsiva de um estado ideal de coisas que se apresenta numa tendência avassaladora de anulação das diferenças e negação do conflito, freqüentemente presente na perversão e nos grupos ideológicos. Compartilhando com Ferenczi (1924/1968) a tese de um estado primário de fusão com o objeto materno, Chasseguet-Smirgel afirma que "o Homem está continuamente buscando o tempo em que era seu próprio ideal - um tempo que coincide com a fusão primária com a mãe" (Chasseguet-Smirgel, 1976, p. 345; minha tradução).

Este momento narcísico inicial seria interrompido pela experiência de desamparo, categoria conceitual fundamental no seu argumento, e teria como conseqüência o surgimento do ideal do $\mathrm{eu}^{3}$ como projeção do narcisismo perdido no objeto. Assim, o ideal apontaria para a tentativa de recuperação do estado narcísico primário que, em última análise, e numa alusão evidente a Rank (1924/1929), Chasseguet-Smirgel entende como estando presente no desejo de retornar ao útero materno, locus privilegiado do narcisismo. A busca de realização do ideal é aquilo que move o humano na sua trajetória subjetiva. Portanto, "o desejo de retorno ao útero materno é o mais fundamental desejo humano (...) nós somos pressionados para frente por um sentimento de nostalgia de um passado maravilhoso (um tempo em que éramos nosso próprio ideal)" (Chasseguet-Smirgel, $1975 / 1985$, p. 27 ; minha tradução).

É crucial, no entanto, que este desejo permaneça como tal, já que sua realização representada pelo retorno ao estado de fusão com a mãe impede o movimento subjetivo e resulta em morte psíquica. Neste sentido, a manutenção do intervalo entre o eu e seu ideal assegura a continuidade psíquica e preserva a diferença entre os sexos e as gerações, pedra fundamental da constituição subjetiva (Chasseguet-Smirgel, 1975/1985).

O universo materno é, por excelência, o locus da Ilusão. O ideal, como substituto do narcisismo perdido com a experiência do desamparo, é projetado na mãe cuja função principal passa a ser facilitar a projeção do ideal antes de tudo no próprio processo de desenvolvimento psíquico, assim como em modelos cada vez mais complexos, até que haja a possibilidade de projeção do ideal no pai edípico. Para Chasseguet-Smirgel, portanto, a figura da mãe é central na trajetória de constituição psíquica, sendo, ao mesmo tempo, o objeto da fusão e aquele que faz a mediação no sentido da separação. É partindo desta premissa que a autora desenvolve sua discussão sobre o lugar da mãe na dinâmica da perversão.

Chasseguet-Smirgel (1971/1984, 1975/1985, 1976, 1986) investigou em profundidade manifestações psíquicas, como a perversão e os grupos ideológicos, que possibilitam a revivência da Ilusão e, portanto, expressam o desejo de negar o desamparo e de excluir o reconhecimento do conflito e da castração, o que se dá prioritariamente através do mecanismo do nivelamento (Chasseguet-Smirgel, 1975/1985; Garcia, 1991). Também o estado de apaixonamento intensifica o narcisismo e estimula a Ilusão através da reunificação do eu com seu ideal, prometendo um retorno ao estado de fusão primária. Na perversão, assim como nos grupos ideológicos, há uma tendência a negar o universo do pai edípico e a preservar a ordem da Ilusão. Da mesma forma com que a mãe do perverso ${ }^{4}$ lhe acena com a possibilidade de plenitude narcísica, fazendo-o acreditar que ele pode ser seu parceiro, o líder ideológico promete o acesso ao universo da Ilusão, domínio da felicidade absoluta e sem arestas.

Em Freudor Reich? Psychoanalysis and illusion, ChasseguetSmirgel e Grunberger (1986) discutem exaustivamente o tema das ideologias, ressaltando que, enquanto a psicanálise freudiana representa uma crítica ao universo da Ilusão, a contribuição reichiana é considerada como um estímulo à reativação da Ilusão, que promove a violência no seu movimento radical de retorno mítico ao estado de fusão original. O ponto de partida dos autores é a suposição de que as instituições e os sistemas sociais e políticos resultam da tradução do espaço psíquico no espaço social, isto é, da projeção do desprazeroso e da agressividade na realidade externa. Assim, as interpretações ideológicas da realidade social visam erradicar o desprazer, apagando as diferenças e negando o conflito e a castração, e expressam o desejo de atingir um estado ideal de coisas, representado pela fusão primária com a mãe. Neste sentido, a ordem pulsional, imutável e inevitável, faz valer sua lógica na construção do social, o que dificulta a mudança e exacerba a hostilidade intragrupal e entre os diferentes grupos. Portanto, com o mesmo ímpeto que, nos grupos ideológicos, os indivíduos negam as diferenças internas e escamoteiam o conflito, eles se tornam intransigentes e violentos com aqueles que deles divergem.

Nos trabalhos que Chasseguet-Smirgel publicou na década de 70, o lugar materno é central na dinâmica da Ilusão, e pouca 
ou nenhuma menção é feita ao pai e suas prerrogativas. A mãe é, ao mesmo tempo, o lugar do ideal e das primeiras frustrações, e cabe a ela facilitar a projeção do ideal, em ultima instância, no pai, com a ressalva de que o ideal representa, ao final das contas, a possibilidade de retorno ao estado inicial e paradisíaco de fusão com o objeto materno. A partir da década de 80 , no entanto, a discussão começa a se centrar em torno do lugar paterno e das vicissitudes da separação, em detrimento da importância quase exclusiva que anteriormente havia sido atribuída ao movimento fusional. O desejo universal de retorno ao estado inicial continua a ser o objeto central da discussão teórica, mas o reconhecimento da intermediação paterna no processo de constituição psíquica possibilita desfechos menos dramáticos e patológicos. No entanto, de uma forma geral, o pensamento de ChasseguetSmirgel se caracteriza por uma definição de ilusão como uma busca avassaladora de retorno a um estado ideal de coisas, que parece existir por si só, sem oposição. Neste sentido, ela afirma a positividade do desejo de atingir o estado mítico de fusão original sem se referir a seu negativo, o que resulta numa leitura em que prevalece uma concepção regressiva de desejo. Uma única tendência estaria em jogo na Ilusão o que justificaria suas conseqüências patológicas. Sua análise do papel da Ilusão nos movimentos utópicos é, neste sentido, exemplar, já que apenas o aspecto totalitário da Utopia é considerado em detrimento da efetividade contestatória e transformadora presente em muitos projetos utópicos (Chasseguet-Smirgel, 1986). A ausência de diferenciação entre Utopia e totalitarismo acaba resultando em interpretações nas quais predomina o caráter regressivo e violento dos movimentos utópicos, sem consideração pela potencial inovador e criativo que possam representar.

Na sua análise da Ilusão, Chasseguet-Smirgel enfatiza as conseqüências patológicas do desejo irrestrito de retorno a um estado mítico de coisas, tomado como ideal, que estaria representado pela fusão originária com a mãe. Assim como Freud, ela aponta para o componente realização de desejo presente na Ilusão, mas suas conclusões diferem no que diz respeito às vicissitudes do desejo. Enquanto para Freud ao desejo sempre se opõe uma força contrária, o que configura um jogo de opostos do qual tanto a neurose quanto as produções culturais se originam, para Chasseguet, na medida em que o desejo parece se sustentar sem oposição, as conseqüências psíquicas são nefastas e devastadoras.

\section{O espaço da ilusão e a criação da cultura}

O estatuto conceitual da ilusão, em Winnicott, é, no mínimo, curioso. Inegavelmente, a categoria ilusão é uma peça central no argumento winnicottiano que se articula com vários outros elementos teóricos, o que lhe garante o estatuto de conceito. No entanto, dos prestigiados dicionários de Newman (2003) e de Abram (2000) não consta o verbete ilusão. Esta constatação nos remete ao próprio significado da ilusão em Winnicott, que aponta para uma situação paradoxal que prescinde de uma solução definitiva acerca de sua natureza específica. Neste sentido, ilusão é e não é, ao mesmo tempo, um conceito winnicottiano, estritamente falando, e, conceitualmente, é justamente este seu caráter intermediário, que potencializa seu valor heurístico e atesta sua pertinência ao campo winnicottiano de produção teórica.

A distinção entre realidade interna e realidade externa é uma tarefa de vida inteira a que se dedicam os humanos, sem muito sucesso. Estamos irremediavelmente condenados à tensão inerente à tentativa de discriminação dentro/fora, situação que se inaugura na relação mãe-bebê e continua pelo resto da vida. A polaridade interno/externo não esgota as possibilidades levantadas pela questão, mas aponta para a necessária postulação de uma terceira área de experiência que deve ser "preservada em qualquer etapa do amadurecimento em qualquer setor da vida" (Dias, 2003, p. 234) e que, no início, se caracteriza pela onipotência. Assim, vejamos: uma mãe suficientemente boa identificada com seu bebê permite que surja uma superposição entre o seio que o bebê acredita estar criando e aquele que lhe é de fato oferecido. Na verdade, para Winnicott (1971c), não há distinção entre o seio oferecido pela mãe e o seio criado pelo bebê já que o bebê mama de um seio que é parte dele mesmo, e a mãe alimenta um bebê que é parte dela própria. Não há relação entre eles, pois fazem parte de uma mesma unidade, mesmo se aos olhos de um observador externo ali estiverem duas pessoas.

É, portanto, no contexto da discussão sobre a construção recíproca da realidade interna e da realidade externa que Winnicott (1953/1971c, 1967/1971a, 1968/1971d) se refere à ilusão de onipotência como a suposição, por parte do bebê, de que o seio que lhe é apresentado e o cuidado que lhe é dispensado foram por ele concebidos e estão sob seu controle onipotente. Em outras palavras, a mãe suficientemente boa possibilita ao bebê a experiência de onipotência de que ele tem a capacidade de criar a realidade externa que ela lhe oferece e, assim, permite que o seu bebê expresse sua criatividade primária e sinta-se criando o objeto subjetivo e determinando os acontecimentos benéficos de que usufrui. Então, em Winnicott, ilusão não aponta para realização de desejo, como em Freud, nem se refere à busca de um estado ideal a ser alcançado, como em Chasseguet-Smirgel. Tampouco diz respeito à ordem pulsional ou serve de proteção contra o desamparo, mas implica na conceituação de um território intermediário entre a realidade pessoal e o mundo externo, que se constitui a partir de um paradoxo cujo valor reside em ser sustentado como tal.

Aos poucos, portanto, e se tudo correr bem, o objeto subjetivo se constitui na condição de que o ambiente suficientemente bom tenha consistência temporal e garanta uma atmosfera de confiabilidade absolutamente necessária. Neste primeiro momento, a dependência e a onipotência são absolutas, o que aponta para um paradoxo: o bebê que se acredita fazendo parte da mãe da qual depende maximamente é o mesmo bebê potente e criativo que se sente criando onipotentemente o ambiente do qual depende em absoluto. No entanto, na medida em que a desilusão gradualmente começa a ocorrer, o controle onipotente cede lugar, possibilitando que o movimento continue e, eventualmente, alcance a aquisição da realidade compartilhada através da construção do objeto objetivamente percebido. Novamente, é a presença de uma mãe suficientemente boa percebendo a necessidade de autonomia de seu bebê e, ao mesmo tempo, dele se desidentificando gradativamente, que garante esta transição sempre incompleta.

Se, neste primeiro momento de dependência absoluta 
(Winnicott, 1965), a ilusão se apresenta como a superposição seio criado/seio oferecido, aos poucos este espaço superposto dá lugar a uma área transicional (Winnicott, 1953/1971c) que suaviza o impacto interno/externo e serve à função de repouso criativo. A transicionalidade ocorre no período de dependência relativa e representa o início da dissolução da unidade mãebebê, conseqüente do processo de desilusão já em curso. É também neste período que a realidade externa começa a se introduzir, colocando em questão o controle onipotente do período anterior.

É só a partir de uma boa experiência inicial na área da ilusão de onipotência (Dias, 2003) que se dá o surgimento desta área intermediária, agora ocupada pelos objetos e fenômenos transicionais que dão corpo à ilusão, e cuja natureza paradoxal não deve ser jamais questionada, isto é, nunca se deve fazer a pergunta crucial: foi criado ou já existia? Para Winnicott (1953/1971c), os fenômenos transicionais constituem o primeiro uso da ilusão e representam uma separação que é, ao mesmo tempo, uma união. Entendemos que aí, quando Winnicott fala de ilusão, não mais se refere à experiência de onipotência na área da ilusão (Dias, 2003) responsável pela criação do objeto subjetivo, mas da ilusão experimentada justamente no momento em que se põe em dúvida a criação onipotente da realidade. $\mathrm{Na}$ verdade, neste momento, a ilusão se faz presente como a primeira experiência de uso de uma possessão não-eu, isto é, de um objeto transicional. Então, a área da ilusão é o espaço intermediário agora ocupado pelo uso do objeto transicional, primeiro símbolo da separação mãe-bebê, que é também uma união e representa a transição da mãe objeto subjetivo para a mãe objetivamente percebida. O símbolo, portanto, na sua positividade como representante da união, só pode se constituir a partir de um movimento de separação ou a partir do trabalho do negativo (Green, 1982, 1993), que possibilita a representação na condição, evidentemente, de que haja uma disponibilidade consistente e continuada da mãe e seus cuidados, no mundo externo.

Sobre os destinos do objeto transicional já sabemos: não será esquecido nem recalcado, mas relegado ao limbo, desinvestido, dando lugar ao imenso campo da cultura. Na concepção winnicottiana o espaço potencial, como território privilegiado da criatividade é o locus de origem do brincar infantil, da arte, da religião, das formações grupais e da cultura, de forma geral, constituindo-se, portanto, no campo de atuação e construção por excelência do agir humano (Winnicott, 1967/1971a). Aqui, a superposição se dá entre a tradição e a novidade, a herança cultural e a inovação criativa numa continuidade herdeira daquela primeira entre a mãe e seu bebê, e o paradoxo assume uma nova feição, mas é sustentado. Mais uma vez não cabe a pergunta "é herdado ou foi inventado", já que o brincar, agora como manifestação cultural, se dá justamente na conjunção destes dois elementos, unindo de uma só vez passado, presente e futuro, numa única experiência fundada na ilusão (Freud, 1976/1908; Winnicott, 1967/1971a). A ampliação dos objetos transicionais para o campo da cultura, no entanto, só se dá quando a área intermediária for preenchida pelo brincar criativo, expressão princeps do humano.

Se tudo correr bem, a área da ilusão de onipotência e a área transicional darão lugar à etapa do uso do objeto (Winnicott, 1968/1971b), momento no qual se constitui o sentido da externalidade a partir do impulso destrutivo do bebê em relação ao objeto subjetivo que, na melhor das hipóteses, sobrevive e não retalia. Neste caso acontece não apenas a criação do objeto externo, mas também a transformação do impulso destrutivo em capacidade de usar o objeto (Dias, 2003) e a existência do fantasiar que, daí em diante, será o palco da destruição do objeto na fantasia, o que garante sua existência na realidade externa, permitindo que seja usado (Winnicott, 1968/1971b, p 130). Nos trabalhos que se referem ao uso do objeto e que discutem, portanto, a criação do sentido de externalidade (Winnicott, 1963/2005a, 1968/2005b, 1968/2005c, 1968/1971b), Winnicott não menciona o papel da ilusão. Mas, em texto posterior, esta temática é retomada mostrando a enorme relevância desta questão no âmbito de sua teoria.

Assim, se o lugar da ilusão no argumento winnicottiano se mostra central ao longo de todo o desenvolvimento emocional primitivo, assim como também na discussão sobre a construção da cultura, é, no entanto, em "The place where we live" (Winnicott, 1968/1971d) que a questão é apresentada de forma ainda mais enfática. Ao voltar a afirmar que a separação é impossível, Winnicott se refere, então, ao lugar onde vivemos como aquele em que se dão a junção e a separação, o eu e o nãoeu, o espaço da ilusão, portanto, como território do paradoxo criativo. A singularidade e a variabilidade das experiências pessoais e as vicissitudes da vida de cada um constituem a marca de origem deste espaço potencial onde a produção do símbolo de certa forma evita a separação... separando. Mais uma vez, o paradoxo, mais uma vez, a ilusão, solo de constituição subjetiva na teoria winnicottiana.

\section{Estado ideal ou espaço potencial?}

Inúmeras são as aproximações e as divergências teóricas entre as definições de ilusão apresentadas por Freud, ChasseguetSmirgel e Winnicott. Uma primeira constatação mostra que Winnicott e Chasseguet-Smirgel derivam suas formulações da matriz enunciada por Freud, interpretando, cada um a seu modo, o legado freudiano do qual se apropriaram e desenvolveram em direções bastante singulares e divergentes. Nossa hipótese, no entanto, é de que, apesar de tão diferentes, suas contribuições podem ser consideradas como complementares e se afiguram como explicações alternativas e extremamente atuais para o entendimento da clinica psicanalítica hoje.

Winnicott e Chasseguet-Smirgel representam tendências teóricas evidentemente distintas, o que resulta em análises que privilegiam conceitos diversos. Enquanto o argumento de Chasseguet-Smirgel deriva diretamente do texto de 1920, tendo, portanto, no conceito de pulsão de morte e no desamparo original seus eixos centrais de sustentação, Winnicott questiona, não apenas a hipótese de uma pulsão de morte, como também a postulação de um estado de desamparo original. Suas concepções teóricas divergentes resultam, então, em definições de ilusão quase antagônicas. Enquanto Chasseguet-Smirgel defende o caráter regressivo do desejo que a ilusão representa, Winnicott afirma a potencialidade criativa do espaço da ilusão, considerado o locus por excelência das experiências singulares. Sugerimos que estas duas diferentes posições podem ser consideradas como 
descrições alternativas de uma normalidade ideal, em Winnicott, e da patologia dos nossos tempos, em Chasseguet-Smirgel. Assim, apesar das críticas que endossamos referentes à visada conservadora presente no pensamento de Chasseguet-Smirgel, que parece levar em conta exclusivamente o aspecto regressivo do desejo, seu entendimento da Ilusão nos remete à patologia dos estados-limite, assim como também a alguns fenômenos grupais contemporâneos. De fato, a intolerância ao desprazer, a impossibilidade de adiar a satisfação, a atração e defesa contra a fusão regressiva, a fragilidade dos limites psíquicos e o recurso a expressões extra-representacionais (Green, 1982) como as passagens ao ato, a toxicomania e os episódios psicossomáticos presentes na clinica contemporânea nos remetem à busca de um estado ideal livre do conflito e, portanto, do outro, que a Ilusão representa, na visão de Chasseguet-Smirgel. Ao que tudo indica estes pacientes não conseguem fazer uso do espaço da ilusão, na concepção winnicottiana, já que em vez de sustentar o paradoxo fazem uso da cisão (Green, 1982) que, dissociando radicalmente realidade interna de realidade externa, impossibilita usufruir da transicionalidade. Conseqüentemente, vêm-se seriamente prejudicados na sua capacidade de construir símbolos e, portanto, de pensar.

A experiência satisfatória do espaço da ilusão como requisito para um psiquismo saudável (Winnicott, 1953/1971c) é um desideratum que nem todos alcançam e, neste sentido, Winnicott nos oferece uma concepção de ilusão que faz parte de um modelo ideal de normalidade. Por outro lado, ChasseguetSmirgel com sua ênfase na fusão regressiva nos fornece uma visão da ilusão como o território próprio da patologia. Ambos, Chasseguet-Smirgel e Winnicott, herdeiros legítimos do texto freudiano, com suas perspectivas tão diferentes sobre a ilusão contribuem para uma reflexão psicanalítica sobre o normal e o patológico na sociedade atual.

\section{Referências}

Abram, J. (2000). A linguagem de Winnicott. Rio de Janeiro: Revinter.

Chasseguet-Smirgel, J. (1976). Some thoughts on the ego ideal. A contribution to the study of the illness of ideality. Psychoanalytic Quarterly, 45(3), 345-373.

Chasseguet-Smirgel, J. (1984). Creativity and perversion. Nova York: Norton. (Texto originalmente publicado em 1971)

Chasseguet-Smirgel, J. (1985). The ego ideal. A psychoanalytic essay on the malady of the ideal. Nova York: Norton. (Texto originalmente publicado em 1975)

Chasseguet-Smirgel. J. (1986). Sexuality and the mind. The role of the father and the mother in the psyche. Nova York: New York University Press.

Chasseguet-Smirgel, J., \& Grunberger, B. (1986). Freud or Reich? Psychoanalysis and illusion. Londres: Free Association Books.

Dias, E. O. (2003). A teoria do amadurecimento de D. W. Winnicott. Rio de Janeiro: Imago.

Ferenczi, S. (1968). Thalassa: A theory of genitality. Nova York: Norton. (Texto originalmente publicado em 1924)

Freud, S. (1976). Escritores criativos e devaneio. In Edição standard brasileira das obras psicológicas completas de Sigmund Freud (Vol. IX, pp. 147-158). Rio de Janeiro: Imago. (Texto original publicado em 1908)

Freud, S. (1974). Sobre o narcisismo: uma introdução. In Edição standard brasileira das obras psicológicas completas de Sigmund Freud (Vol. XIV, pp. 85119). Rio de Janeiro: Imago. (Texto original publicado em 1914)

Freud, S. (1976). Além do princípio do prazer. In Edição standard brasileira das obras psicológicas completas de Sigmund Freud (Vol. XVIII, pp. 13-85). Rio de Janeiro: Imago. (Texto original publicado em 1920)

Freud, S. (1976). Psicologia de grupo e a análise do ego. In Edição standard brasileira das obras psicológicas completas de Sigmund Freud (Vol. XVIII, pp. 89-179). Rio de Janeiro: Imago. (Texto original publicado em 1921)

Freud, S. (1974). O futuro de uma ilusão. In Edição standard brasileira das obras psicológicas completas de Sigmund Freud (Vol. XXI, pp. 13-71). Rio de Janeiro: Imago. (Texto original publicado em 1927)

Freud, S. (1976). Ansiedade e vida instintual [Novas conferências introdutórias sobre a Psicanálise]. In Edição standard brasileira das obras psicológicas completas de Sigmund Freud (Vol. XXII, pp. 103-138). Rio de Janeiro: Imago. (Texto original publicado em 1933)

Garcia, C. A. (1988). Illusion and sexuality. A contribution to the study of the ego ideal. Tese de doutorado não-publicada, The Wright Institute Graduate School of Psychology, Berkeley, EUA.

Garcia, C. A. (1991). Ilusão e família: uma discussão sobre o ideal do ego. In J. Vilhena (Org.), Escutando a família. Uma abordagem psicanalitica (pp. 69-80). Rio de Janeiro: Relume Dumará.

Green, A. (1982). La double limite. Nouvelle Revue de Psychanalyse, (25), 267-283.

Green, A. (1993). Le travail du négatif. Paris: Éditions de Minuit.

Mitchell, J. (1987). Resenha de Creativity and perversion. The International Journal of Psychoanalysis, 68(1), 131-133.

Newman, A. (2003). As idéias de D. W. Winnicott. Rio de Janeiro: Imago.

Rank, O. (1929). The trauma of birth. Nova York: Harcourt Brace. (Texto original publicado em 1924)

Rittenberg, S. (1987). Resenha de Creativity and perversion. The International Review of Psychoanalysis, 14, 130-132.

Winnicott, D. W. (1971c). Transitional objects and transitional phenomena. In Playing and reality (pp. 1-25). Londres: Tavistock. (Texto original publicado em 1953)

Winnicott, D. W. (2005a). Um sonho de D.W.W. relacionado a uma resenha de um livro de Jung. In C. Winnicott, R. Shepherd, \& M. Davis (Orgs.), Explorações psicanaliticas W. W. Winnicott (pp. 178-179). Porto Alegre: Artmed. (Texto original publicado em 1963)

Winnicott, D. W. (1965). From dependence towards independence in the development of the individual. In The maturational processes and the facilitating environment (pp. 83-91). Nova York: International Universities Press.

Winnicott, D. W. (1971a). The location of cultural experience. In Playing and reality (pp. 95-103). Londres: Tavistock. (Texto original publicado em 1967)

Winnicott, D. W. (2005b). O uso da palavra uso In C. Winnicott, R. Shepherd, \& M. Davis (Orgs.), Explorações psicanalíticas W. W. Winnicott (pp. 178-179). Porto Alegre: Artmed. (Texto original publicado em 1968)

Winnicott, D. W. (2005c). Comentários sobre meu artigo "O uso de um objeto" (pp. 185-186). In C. Winnicott, R. Shepherd, \& M. Davis (Orgs.), Explorações psicanaliticas W. W. Winnicott (pp. 178-179). Porto Alegre: Artmed. (Texto original publicado em 1968)

Winnicott, D. W. (1971b). The use of an object and relating through identifications. In Playing and reality (pp. 86-94). Londres: Tavistock. (Texto original publicado em 1968)

Winnicott, D. W. (1971d). The place where we live. In Playing and reality (pp. 104-110). Londres: Tavistock Publications. 
${ }^{1}$ A diferença eu ideal/ideal do eu, que a psicanálise pós-freudiana construiu a partir deste texto, não nos interessa neste momento e será, portanto, desconsiderada.

${ }^{2}$ Em Chasseguet-Smirgel, Ilusão é grafada com maiúscula na medida em que se refere a um amplo campo de emergência psíquica, mais do que a fenômenos pontuais e circunscritos.

${ }^{3}$ Chasseguet-Smirgel discutiu extensivamente a problemática do ideal em psicanálise sempre utilizando o termo ideal do $e u$, sem trabalhar, no entanto, a distinção ideal do eu/eu ideal presente em autores pós-freudianos.

${ }^{4}$ A relação entre perversão e criatividade foi extensivamente discutida por Chasseguet-Smirgel tendo sido criticada por sua visão moralista da perversão e sua definição estreita de criatividade (cf Mitchell, 1987; e Rittenberg, 1987).

Claudia Amorim Garcia, doutora em Psicologia Clínica pelo Wright Institute, Berkely (EUA), é professora associada no Departamento de Psicologia da Pontifícia Universidade Católica do Rio de Janeiro e psicanalista membro do Círculo Psicanalítico do Rio de Janeiro. Endereço para correspondência: Rua General Glicério 335, apto 1202 (Laranjeiras); Rio de Janeiro, RJ; CEP 22245-120. E-mail: clauag@uol.com.br 